\title{
Decision-Making Analysis using Arduino-Based Electroencephalography (EEG): An Exploratory Study for Marketing Strategy
}

\author{
Ahmad Faiz Yazid ${ }^{1}$, Siti Munirah Mohd ${ }^{2 *}$, Abdul Razzak Khan Rustum Ali Khan ${ }^{3}$ \\ Shafinah Kamarudin ${ }^{4}$, Nurhidaya Mohamad Jan ${ }^{5}$ \\ Advanced Technology and Sustainable Research Group, Kolej GENIUS Insan ${ }^{1,3}$ \\ Universiti Sains Islam Malaysia (USIM), Negeri Sembilan, Malaysia, ${ }^{1,3}$ \\ Senior Lecturer, Kolej GENIUS Insan, Universiti Sains Islam Malaysia (USIM), Negeri Sembilan, Malaysia ${ }^{2,5}$ \\ Senior Lecturer, Department of Science and Technology, Faculty of Humanity, Management and Science ${ }^{4}$ \\ Universiti Putra Malaysia (UPM) Bintulu Campus, Bintulu, Sarawak ${ }^{4}$
}

\begin{abstract}
Business technology has brought conventional marketing methods to the next level. These emerging integrated technologies has contributed to the growth and understanding of the consumer decision making process. Several studies have attempted to evaluate media content, especially on video advertising or TV commercials using various neuroimaging techniques such as the electroencephalography (EEG) device. Currently, the use of neuroscience in Malaysia's marketing research is very limited due to its limited adoption as an emerging technology in this field. This research uncovers the neuroscientific approach, particularly through the use of an EEG device; examining consumers' responses in terms of brain wave signals and cognition. A proposed theoretical framework on the factors affecting visual stimulus (movement, color, shape, and light) during the decision-making process by watching video advertising had been customized using two conceptual models of sensory stimulation. Ten respondents participated in the experiment to investigate the spectral changes of alpha brain wave signals detected in the occipital lobe. A 2-channel Arduinobased EEG device from Backyard Brains and Spike Recorder software was used to analyze the EEG signal through Fast Fourier Transform (FFT) method. Results obtained from the investigated population showed that there was statistically significant brain wave activity during the observation of the video advertising which demonstrated the interconnection with short-term memory through visual stimulus. Application of the neuroscience tool helped to explore consumer brain responses towards marketing stimuli with regards to the consumers' decision-making processes. This study manifests a useful tool for neuromarketing and concludes with a discussion, together with recommendations on the way forward.
\end{abstract}

Keywords-Arduino-based electroencephalography (EEG); neuromarketing; short-term memory; TV commercials; visual cognition

\section{INTRODUCTION}

Promoting products is a significant part of business, which is a relentless and ever-evolving condition. The increasing customer density and changing methods of doing business has resulted in huge amounts of data which contrasts with the business research condition from a couple of decades back. For example, the idea of 4Ps (product, place, price, and promotion) in advertising exercises includes a progression of instruments which organizations use to accomplish their objectives [1].The promoting blend alludes to an assortment of different devices that organizations regularly use to obtain the ideal reaction from their customers [2]. This practice has been broadly embraced in the field of marketing promotions, particularly for showcasing procedures [3]. Likewise, videobased advertisements or commercials can be viewed as one of the quickest developing forms of online advertising which happen within customers' inner thoughts, practically $80 \%$ of new items being promoted will fade into obscurity within a year [4]. Obtaining a better insight into the purchaser's dynamic though procedures via a neuroscientific approach assist organizations in making educated business choices through the assessment of the business viability. It is a basic tenement for advertisers to investigate and grasp human behavior in order to be able to lessen customer dissatisfaction while increasing customer loyalty in order to increase revenue and income stream stability [5].

Up until recent times, the vast majority of organizations still depend on conventional promotional devices, such as studies, examinations, and center gatherings, all of which take a considerable amount of time. These methods are all aimed at trying to provide comprehension in regard to consumer reactions in order to be able to build a better product to satisfy the customer [6]. Thus, in order to reduce the amount of time required to gauge customer reactions while increasing accuracy of data, the application of neuroscience is seen as a possible advancement in marketing methodology. New neuroscience advances have empowered organizations connect more intimately with customers to better cater to their needs. Neuroscience aids in the analysis of a brand or product's potential prior to promotions, which is of particular value to organizations in terms of validity of data and reduction in costs [7]. The advent of "neuromarketing" is fast overtaking statistical surveys as the preferred means to gain customer insight [8].

On the report of Google Trends in 2020, the trend of interest on neuromarketing searched worldwide started from 2004 until present (October 2020) is increasing significantly.

\footnotetext{
*Corresponding Author
} 
The findings from several research related to neuromarketing are becoming increasingly important in providing meaningful data to the marketing industry as the area of interest continues to grow. Taken as a whole, it can be inferred that the basic concept of neuromarketing is the use of neuroscience tools to better grasp consumer behavior and to analyze the efficacy of advertising actions from the marketing stimulation, covering the aspects of unconscious and emotional response.

Based on the inquiry targets, the use of neuromarketing can be used by both business activity and research field. Specific to the field of consumer behavior, neuromarketing provides important perspectives and methods into consumer research [9]. This is confirmed by researchers who stated that neuromarketing offers a broad range of knowledge, aggregating in the subconscious mind to behavioral data which guides consumers in their decision- making process [10]. Thus, it was also reported that the research of neuromarketing will measure emotional engagement, memory retention, purchasing intention, novelty, consumer awareness and interest, positioning, product design and creativity, advertisement efficacy, decision-making, online experience, and entertainment performance [11].

In particular, neuroscience helps to understand the role of consumers' inner emotional responses, which play an important part in decision making process [12]. This evidence is supported by the idea of neuroscience seeks to understand the underlying complex of thoughts such as reasoning, decision making, object representation, emotion, memory and consumer responses to marketing [13]. Neuroscience is also associated with the basis for understanding how consumers create, store, recall and relate to information such as brands in everyday life [14]. The findings obtained from studies in neuromarketing give insight into the attitude of the customer that traditional marketing research approaches cannot deliver.

The utilization of neuroscience in Malaysia's is currently limited as it is a new field with few proponents. The fast adoption and advances in the field of neuromarketing in Europe and the United States will inevitably lead to a scramble to adopt this method in Malaysia [15]. Therefore, fast tracking localized studies in this particular field becomes of importance to ensure sufficient preparedness when the time comes. Advertisers need to familiarize themselves with the concepts and practices required of neuroscience in order to stay competitive in providing for the consumers wants and needs.

This research endeavors to inspect local consumers' reactions towards video advertising in terms of their decisionmaking process; through the use of the neuroscientific method utilizing electroencephalogram (EEG). The present study hopes to encourage advertisers to be more alert towards the customer decision making process in order for them to produce higher impact video-based advertisements which will be more effective in terms of marketing. The use of neuromarketing will reduce disappointments by aiding analysts and organizations to create more effective content which aligns with customer requirements.

This study addresses three main questions as follows; (i) How can neuromarketing be applied effectively in the processing of visual information through video-based advertising?; (ii) What happens in the human brain during the purchase making decision process through advertising?; (iii) Is it possible to identify the roots of observed and noticed consumer behavior patterns in processes of human brain activity?

The objectives of this study are; (i) To investigate the spectral changes of alpha brain wave signal detected from 2channel Arduino-based EEG device using the Fast Fourier Transform (FFT) method; and (ii) To identify the contributing factors from video advertising in the activation of brain wave signal towards decision making processes by testing the cognitive response of short-term memory.

The paper is structured as follows. Section II presents the proposed theoretical framework used in this study with relevant literary highlights along with critical and creative reviews towards understanding the research concept. Section III shows the process of acquisition of the EEG signal from the human brain to the computer system by using Spike Recorder software. The project flow in terms of the application of working principles and procedures in conducting the experiment is demonstrated in detail. Section IV discusses the result of this study. The discussion involves the results of the EEG signal which was acquired from test subjects and the result of signal processing through the Fast Fourier Transform (FFT) method. The final discussion details how the EEG signal is affected by several factors applied in video-based advertisements. Finally, Section V and VI explain the conclusion and recommendations for this project. Further research is also addressed pertaining to marketing strategy and other factors involved in advertising required to activate the brain wave signal of consumers towards their decision-making process.

\section{THEORETICAL FRAMEWORK}

The proposed framework (Fig. 1) is constructed to show the variables corresponding to the research. This framework is designed by taking into account the work of other researchers and furthering their concepts. The model can be divided into parameter (catalytic factors) selection from the two conceptual models of sensory stimulation (Sensory Stimuli Model [16] and Map of Dynamic Stimuli [17]). The selection of parameters focuses mainly on visualization as it is a major stimulus associated with consumer cognition when watching video advertising or $\mathrm{TV}$ commercials. Information related to visualization is analyzed in greater detail to determine factors affecting the stimulus.

It is readily apparent throughout various evidences that assessments of consumer behavior in purchasing decisions were affected by visual stimuli, in which relevant to the usage and quantity in product selection [18]. This results to the role of visual stimuli seem to be more significant, even in the absence of verbal information about an item. Overall, it is easier to concentrate on an item with the use of graphic imagery. This is particularly true in a competitive clutter situation, where visuals provide a sense of value and nurture strong engagements with a brand, thus, contribute to the possible decision to purchase due to positive influence on consumer judgment and purchase decision. 


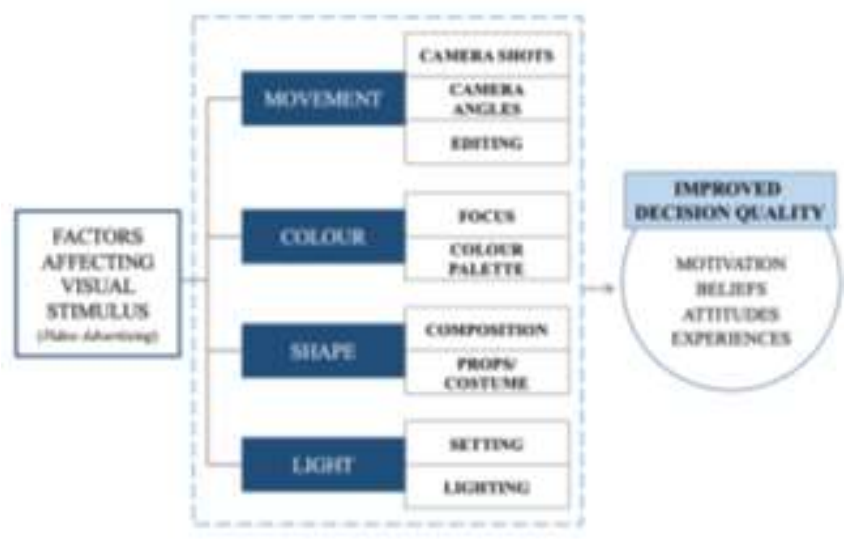

Fig. 1. Theoretical Framework of Relationship between Independent Variable and Dependent Variable.

This particular framework contains both dependent and independent variables. The dependent variable is the decisionmaking process of consumers (observed through the activation of brain wave signal analysis - neuroscience technique). The independent variable is the factors affecting the visual stimulus, consisting of movement, color, shape, and light.

\section{MATERIALS AND METHODS}

\section{A. Experimental Design}

A total of ten (10) respondents, comprising five male subjects and five female subjects, with an age range of between 16 and 17 years, participated as part in this investigation. All respondents were secondary school students from Kolej PERMATA Insan, Universiti Sains Islam Malaysia (USIM). The participants were well acquainted with promotional videos and notable brands. All participants did not have any history of clinical disease, for example, cognitive/mental/psychological disorders. Prior to the start of testing, an introductory presentation regarding the specific exploration, time length, and motivation behind the study was presented to respondents.

\section{B. Experimental Procedures}

The experiment was carried out according to stringent protocols with non-disclosure clause and permissions for gathering EEG signals obtained from the participants. A quiet room with dim lighting was used to avoid external interruption. Participants were seated following an ordered seating scheme and the LCD screen was placed 5 meters away from them. The EEG device was introduced to participants at this time and a short clarification about the test was relayed to them orally. The headband of the 2-channel Arduino-based EEG gadget was directly connected to a laptop (Macbook Pro) pre-installed with an open-access version of EEG recording analysis (Spike Recorder) software. All connections were examined prior to the test to ensure no disruptions and full functionality during the analysis.

The trial comprised of four segments; one session for preparation, two sessions for the EEG recording, and an additional session for the survey. Prior to the start of each session, a full white background picture was screened to the respondents to ensure an unbiased state condition. When the brain wave signal of each respondent reached a constant level, the video advertisement of a notable well-known fast food brand (McDonald's Malaysia) was introduced and participants were made to view a repeat of the commercial during the third session, whereby the commercial was played exactly 30 seconds after which a period of 2.5 minutes was allocated to stabilize brain waves back into a neutral condition. After the repeated viewing of the advertisement, a short-self assessment was conducted. During the final session, respondents completed a poll to assess the commercial. During this final stage respondents were asked to review and recall the specific scenes from the TV commercial for the purpose of evaluating their short-term index. Finally, respondents were required to state or choose the reasons why a particular scene was memorable enough to trigger their short-term memory.

\section{Data Analysis}

The acquired EEG signals were firstly pre-processed using the Arduino Uno microcontroller and Fast Fourier Transform (FFT) method. This was done to derive the statistical features of the alpha wave recorded from each subject. The extracted features were subsequently matched with the film segments to investigate the spectral changes of the subjects' brain wave signal regarding the product advertisements.

The Fourier Transform are the data analysis programs used for the purpose of generating spectrograms, which showed the changes in frequency content of a signal over time. An opensource Arduino Code was used to send data from the computer board running the macOS Catalina (Version 10.15) system. The resulting brain wave signals from this process were detected and analyzed for this study. For the Spike Recorder software, a spectrogram within a certain frequency band was set up to appear below the moving EEG trace of the brain wave signal. The present study also applied a qualitative research methodology through non-probability sampling using a semi-structured survey among the ten individuals who were subjected to the recording of brain wave signals using the EEG device. This survey was conducted for approximately 15 minutes after the EEG experiment to determine the subjects' perceptions and cognitions with regards to the video advertisement. This survey evaluated the subjects' cognitive responses through short-term memory index in order to discover the factors in video advertising that could influence the decision making of consumers via visual stimulus.

\section{RESUlTS AND DisCUSSIONS}

This section depicts the investigation of the spectral changes in the alpha brain wave signal detected from the 2channel Arduino-based EEG device using Fast Fourier Transform (FFT) method and the identification of the contributing factors from video advertising in the activation of brain wave signal towards the decision making process by testing the cognitive response of short-term memory for all participants.

\section{A. Spectrum Analysis using Fast Fourier Transform (FFT) Method}

The breakdown of results collected from the participants is shown through a progression of figures demonstrating the measurably huge contrasts of brain wave signal activated for 
the dataset at the recurrence band $(10-40 \mathrm{~Hz})$ of spectrographic analysis. The figures comprise a progression of result boards, each containing two pictures; the top figure represents a frame of the video advertising whereas the lower one shows the corresponding mean of brain wave activity, and the temporal axis beat the time of commercial. In Fig. 2, the primary arrangement of seven film sections taken at every five second from the earliest starting point of the commercial, navigating the entire length of a specific commercial spot. Thorough auditing of each strip highlight shows the tracking of the mean brain wave activity changes according to scenes in the video advertisement viewed by the respondents.

The difference in brain wave activity becomes increasingly obvious in Fig. 3, made out of three boards representing the first, the middle, and the last frame of the video advertisement, respectively. The corresponding mean of the brain wave activity completes each board of the figure. By observing these three panels, it is clear how the middle part of the commercial shows activation of occipital zone with measurable contrasts, while there are two peaks of activity (greater reoccurring green spots) towards the beginning and the end of the clip; revealed the increases of alpha wave power in the brain wave signal.

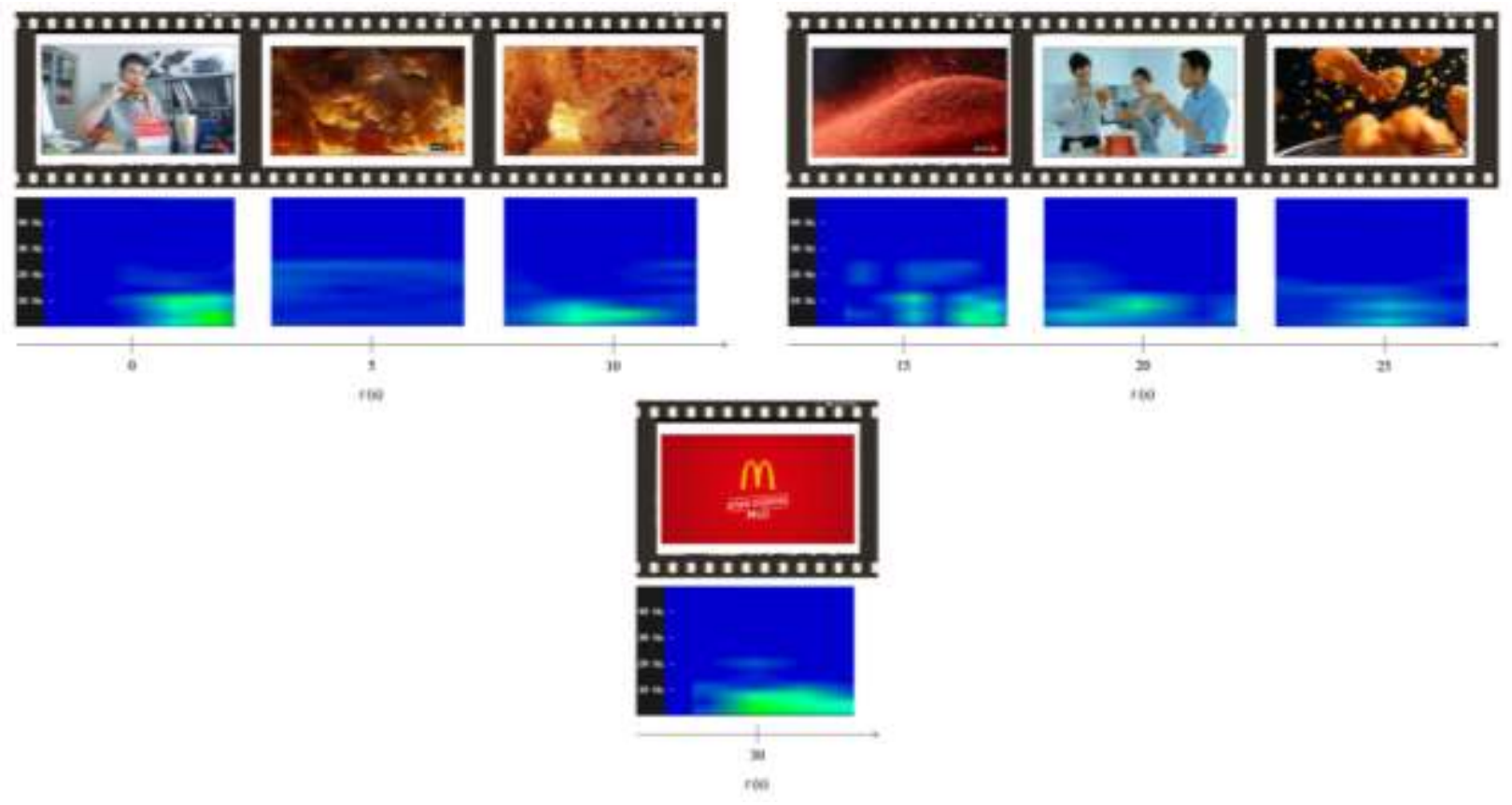

Fig. 2. Tracking of the Brain wave Activity in the Frequency Band within the Time Spots of Every Five Seconds, Across Seven Film Segments.

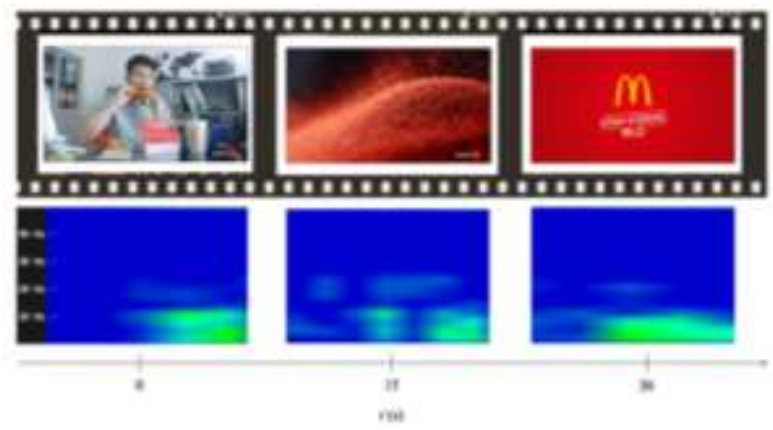

Fig. 3. Tracking of the Brain wave Activity Across Three Panels of the Total Film Sequence. 

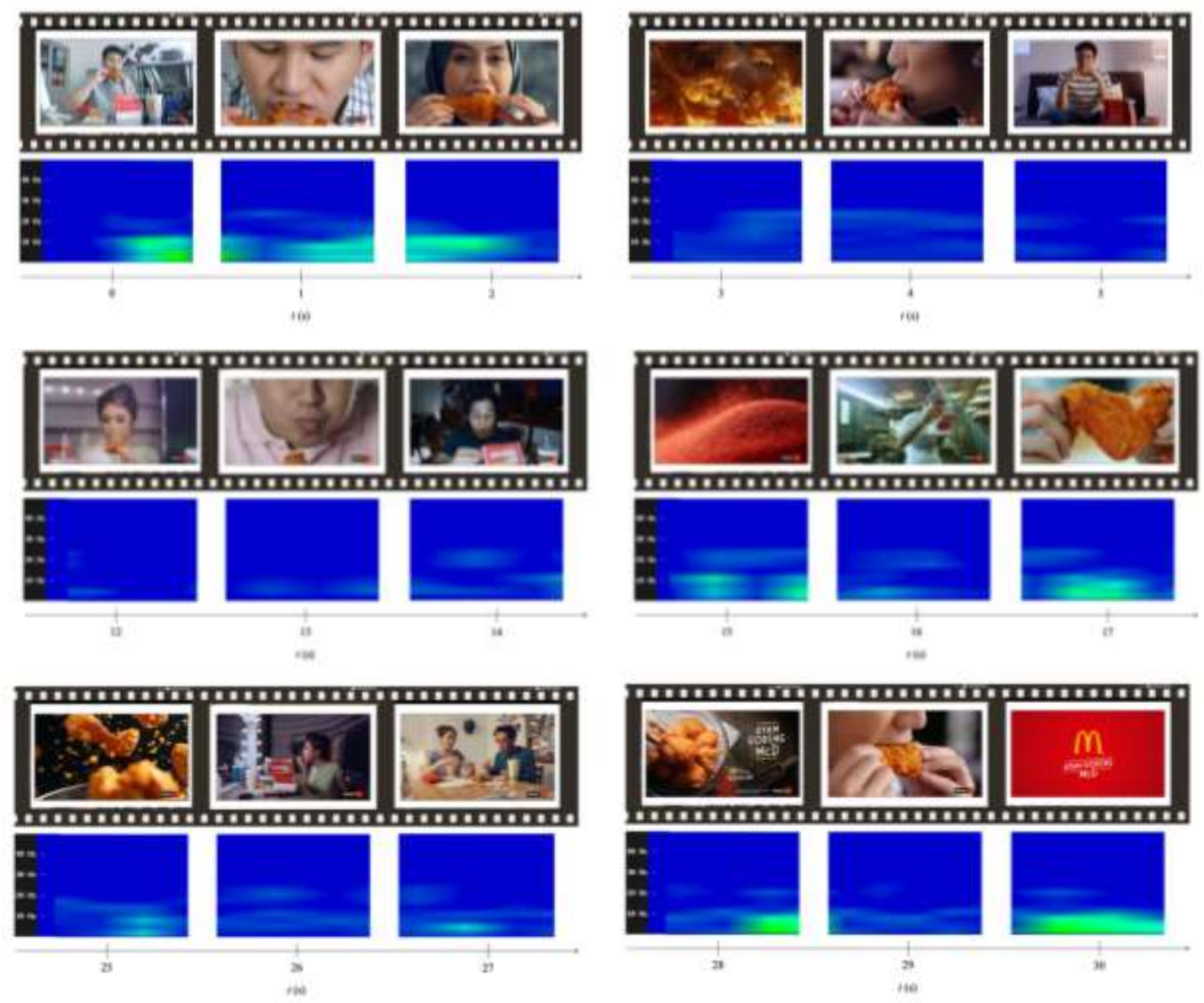

Fig. 4. Tracking of the Brain wave Activity in the Frequency Band for the First Five Seconds, the Middle Five Seconds, and the Last Five Seconds of the Commercial Spot.

The implementation of neuroscience approach in advertising is growing. It is believed that frequency of branding product exposure in a particular TV commercial might contribute towards the effectiveness of the advertising. This statement is parallel to the experiment that indicated containing multiple exposures of the branding products had a positive impact on the preference for the commercial, in which resulted to higher brain wave activity within several major regions including the frontal, bilateral occipital, and limbic system [21]. Ultimately, there is a need for research to help marketers cultivate effective and memorable marketing campaigns, hence, this study design will contribute to the consumer's decision-making process.

\section{B. Cognitive Testing for Short-Term Memory}

At the start of the survey, respondents needed to furnish their demographic details. The profile of the respondents is shown in Table I below. Based on Table I, the proportion of male to female respondents were equal 50\%:50\%. The mean age distribution of the respondents was the age group of above 16 years old as the dominant age group ( $\mathrm{f}=9,90.0 \%$ ) compared to the age group of below 17 years old $(\mathrm{f}=1$,
$10.0 \%)$. All respondents $(100.0 \%)$ were familiar with video advertising or TV commercials.

Apart from the demographic background questions, all respondents were asked two other questions. Firstly, respondents were asked to rate the advertisement based on several qualities. Secondly, they were asked how memorable the advertisement was. Responses were rated on a five-point Likert-type scale ranging from ' 1 ' to ' 5 ', which represents in ascending order strongly disagree, disagree, partially agree, agree, and strongly agree. Participants responses towards the commercial are as shown in Table II.

TABLE I. DEMOGRAPHIC PROFILE OF RESPONDENTS

\begin{tabular}{|l|l|l|l|}
\hline & & Frequency & Percentage (\%) \\
\hline \multirow{2}{*}{ Gender } & Male & 5 & 50.0 \\
& Female & 5 & 50.0 \\
\hline \multirow{2}{*}{ Age } & $>16$ y/o & 9 & 90.0 \\
& $<17$ y/o & 1 & 10.0 \\
\hline Familiar with video & Yes & 10 & 100.0 \\
advertising? & No & 0 & 0.0 \\
\hline
\end{tabular}


TABLE II. REGRESSION ANALYSIS OF THE SURVEY

\begin{tabular}{|l|l|l|}
\hline & Mean & SD \\
\hline Q1) Rate the advertisement based on the following: & & \\
Comprehension & 4.50 & 0.25 \\
Message & 4.00 & 0.45 \\
Impact & 4.80 & 0.16 \\
Clarity & 4.20 & 0.40 \\
\hline Q2) How memorable was the advertisement? & 4.90 & 0.30 \\
\hline
\end{tabular}

From Table II, it is shown that the majority of respondents chose strongly agrees or agrees options when filling out the questionnaire. All the means computed are above 4. All of the questions have a mean equal to a minimum of 4.00 and maximum of 4.90 , which denotes positive responses from participant. Next respondents were asked to list the most memorable scene from the video advertisement they were shown. Based on the responses, the theme and issues of the description are linked and tailored to the four factors affecting visual stimulus as outlined in the theoretical framework of this study.

Table III shows the detail of the responses from each memorable scene according to the factors outlined in the proposed framework. There were five respondents (Respondents 1, 3, 5, 7, and 8) who stated that the element of movement an obvious factor being displayed in the video advertisement. Individual elements include camera shots, camera angles, and editing combined to help consumers to mark and remember specific scenes.

A total of nine respondents expressed their agreement that the color factor is what makes the video advertisement memorable. The focus and color palette significantly affect the color gradient of the whole video frame. The factor of shape consists of the composition of props and costumes worn by the characters in specific scenes. This factor controls how the scene is set or staged. Six respondents noted that the shape factor affected their memory for certain scenes in the video. Another factor which was highlighted by seven respondents is the light factor; this is in line with the research framework. Lighting is a very important aspect of communication which influences the subconscious perception of what the commercial is showing.

As a whole, the EEG technique of spectrogram analysis was deemed to have enabled the researcher to track subjects' brain wave activity while they were observing the commercial. In such a manner, it is possible to acquire a broad measure of the reconstructed brain wave signals by means of a simple FFT method. This allows the researcher to distinguish the different activities within alternating advertising scenes. To sum it up, the present study managed to analyze the brain wave detected brain wave activities, as a result of visual stimulus in response to the video advertisement. This provides proof that the neuroscience technique of EEG can be implemented for marketing research, involving the measurement of consumer's brain wave activity.

Subsequently, it was found that respondents provided differing views on the factors affecting their cognitive responses of short-term memory regarding the video advertisement. All of the four factors are described in depth by the majority of respondents in terms of the scenes they remember throughout the 30 videos. It was found that the majority of respondents $(\mathrm{f}=9,90.0 \%)$ agreed that color, including the elements of focus and color palette, played a major role in garnering consumer responses, through the triggering of their short-term memory. In contrast, movement factors such as camera shots, camera angles, and editing garnered the least agreement amongst respondents $(\mathrm{f}=5$, $50.0 \%$ ) as an influence on consumer's preference.

TABLE III. MEMORABLE ELEMENTS IN THE VIDEO ADVERTISEMENT BASED ON RESPONDENTS' RESPONSES

\begin{tabular}{|c|c|}
\hline Factors (Elements) & Responses \\
\hline \multicolumn{2}{|l|}{ Movement } \\
\hline Camera Shots & $\begin{array}{l}\text { "The scene of a female with hijab shows a very } \\
\text { interesting close-up. The head and shoulders of the } \\
\text { character are clearly focused." (Respondent } 3,7 \text {, } \\
\text { and } 8 \text { ) }\end{array}$ \\
\hline Camera Angles & $\begin{array}{l}\text { "The placement of a chicken bucket at the end of } \\
\text { the video has been captured at high angle. The } \\
\text { camera is placed above eye level, looking down." } \\
\text { (Respondent } 1 \text { and } 7 \text { ) }\end{array}$ \\
\hline Editing & $\begin{array}{l}\text { "The continuity of each character's scene with a } \\
\text { close-up, everyone biting the chicken. When one } \\
\text { shot ends and another one begins." (Respondent 5) }\end{array}$ \\
\hline \multicolumn{2}{|l|}{ Color } \\
\hline Focus & $\begin{array}{l}\text { "Footage of people biting crunchy chickens is } \\
\text { shown in shallow focus. When one part of the } \\
\text { image is in focus, and another part is not." } \\
\text { (Respondent } 1,4,5,6,8 \text {, and 9) } \\
\text { "Special effect for chicken being fried in oil. When } \\
\text { the overall frame is blurry, out of focus." } \\
\text { (Respondent } 2,3,5 \text {, and 10) }\end{array}$ \\
\hline Color palette & $\begin{array}{l}\text { "Trademark of McDonald's logo at the end of } \\
\text { commercial. The range of colors chosen for the } \\
\text { scene is well blend; red and yellow." (Respondent } \\
1,4 \text {, and } 10 \text { ) }\end{array}$ \\
\hline \multicolumn{2}{|l|}{ Shape } \\
\hline Composition & $\begin{array}{l}\text { "The first scene describes how things are } \\
\text { positioned in the frame." (Respondent } 3 \text { and 4) } \\
\text { "The role of husband and wife characters } \\
\text { expresses strong family bond, sharing chicken } \\
\text { together." (Respondent } 2 \text { and 5) }\end{array}$ \\
\hline Props/ Costumes & $\begin{array}{l}\text { "The items used for background and anything } \\
\text { worn by actor is appropriate, shot in the office." } \\
\text { (Respondent } 1 \text { and } 6 \text { ) }\end{array}$ \\
\hline \multicolumn{2}{|l|}{ Light } \\
\hline Setting & $\begin{array}{l}\text { "Footage of chicken is cooked in a frying pan. } \\
\text { Encloses where a scene takes place." (Respondent } \\
2 \text { and 7) }\end{array}$ \\
\hline Lighting & $\begin{array}{l}\text { "Special effect customized in the scene of chicken } \\
\text { covered with spices. Like the chicken being placed } \\
\text { in a spotlight." } \\
\text { (Respondent } 1,2,3,4,5,7 \text {, and 9) }\end{array}$ \\
\hline
\end{tabular}

\section{FUTURE SCOPE}

Thanks to neurotechnological advancements, analysis of consumer brain wave movement is presently achievable, which means both researchers and advertisers have a suitable 
method to gather greater comprehension of consumers behavior. The utilization of an EEG device is paving the way for future consumer research and will improve on the traditional methods using statistical surveying methods.

From the research and post-experiment interviews conducted, researcher can conclude that an advertisement which is more likely to attract and influence consumer's purchasing making decision is the one that fulfills several factors affecting the visual stimulus. "Look More, Like More". This demonstrated by the brain wave activation detected from alpha wave signal in the occipital lobe. The effects of purchaser's behavior, promotion, marketing, pricing, product circulation, and decision making can be analyzed from a much more scientific base Further research on consumer cognition and their visual attention will allow researchers to have greater understandings of human behavior for use in a wide array of fields including marketing, health care, personal traits and wellness.

Further research is this field is expected to motivate researchers, academicians, and professionals to further develop the field of marketing and advertising research of consumers through the application of neuroscience.

\section{CONCLUSION}

This research presents the application of an EEG device as a neuroscience technique in the field of neuromarketing, in conjunction with the development of a theoretical framework based on the two previous conceptual models of sensory stimulation, particularly regarding the visualization aspect. The findings of this research are the results of the fulfillment of the two objectives set at the beginning of the study.

The first objective of this research is to investigate the spectral changes of alpha brain wave signal detected from a 2channel Arduino-based EEG device using Fast Fourier Transform (FFT) method. The fulfillment of the first objective answers the first and second research questions. The main finding of this research in the context of the first objective is the method of tracking the mean of alpha brain wave activity through spectrographic analysis, as a result of visual stimulus in response to the video advertisement.

The second objective is to identify the contributing factors from the video advertisement in the activation of brain wave signals towards the decision-making process which was triggered by the cognitive response of short-term memory. The implementation of this second objective addresses the third research question. The research finding in the context of the second objective is the evidence of the effectiveness of the theoretical framework development derived from the two preceding conceptual models. Factors affecting visual stimulus underlined in the framework (movement, color, shape, and light) were proven to be major guidelines for the production of video advertisement designed to influence the consumer decision making process.

The theoretical framework of this research shows proof that the visual attention of human beings is reflective of their purchasing behavior. It is hoped that this study will improve the quality of the decision-making process, influenced by the cognitive response of short-term memory. Consumers' experiences throughout their lives are registered in their memory which means that their prior experiences which are collected in the first stage of memory can have a big impact on their future experiences in terms of how they react and respond.

The current study has usefulness beyond academia as it will be of great use to the industry, in practical terms the study provides a novel application of the EEG technology in the field neuromarketing. The results and methods demonstrated in this study will be helpful to those involved in the field of marketing and advertising. This will provide a more efficient method to obtain usable consumer data to increase marketing effectiveness.

\section{ACKNOWLEDGMENT}

The authors would like to acknowledge the contributions of the anonymous reviewers whose valuable comments and insightful suggestions led to the improvement of the preliminary version of this paper.

\section{REFERENCES}

[1] Alizade, R., Mehrani, H., \& Didekhani, H. (2014). A Study on the Effect of Selected Marketing Mix Elements on Brand Equity with Mediating Role of Brand Equity in Etka Chain Stores-Golestan Province. Kuwait Chapter of Arabian Journal of Business and Management Review, 3(11), 184-193.

[2] Khan, M.T. (2014). The Concept of 'Marketing Mix' and its Elements (A Conceptual Review Paper). International Journal of Information, Business and Management, 6(2), 95- 107.

[3] Heding, T., Knudtzen, C. F., \& Bjerre, M. (2009). Brand Management Research, Theory and Practice. New York: Routledge.

[4] Cruz, C. L., de Medeiros, J. F., Hermes, L. R., Marcon, A., \& Marcon, É. (2016). Neuromarketing and the advances in the consumer behaviour studies: A systematic review of the literature. International Journal of Business and Globalisation, 17(3), 330-351.

[5] Mehta, B., \& Panda, R. (2015). Neuromarketing-Contour between the Proximate and the Ultimate level of Consumer Decision Making. IFRSA Business Review, 5(1), 1-5.

[6] McDowell, W. S., \& Dick, S. J. (2013). The Marketing of Neuromarketing: Brand Differentiation Strategies Employed by Prominent Neuromarketing Firms to Attract Media Clients. Journal of Media Business Studies, 10(1), 25-40.

[7] Lassere, A. (2014, October 26). The Marketing Corner: 'Brave New World'. Retrieved from The Epoch Times: https://www.theepochtimes.com/the-marketing-corner-brave-newworld_1043889.html

[8] Ciprian-Marcel, P., Lăcrămioara, R., Ioana, M. A., \& Maria, Z. M. (2009). Neuromarketing - Getting Inside the Customer's Mind. Annals of Faculty of Economics, 18(1), 804-807.

[9] Genco, S. J., Pohlmann, A. P., \& Steidl, P. (2013). Neuromarketing for Dummies. Mississauga: John Wiley \& Sons Canada, Ltd.

[10] Colaferro, C. A., \& Crescitelli , E. (2014). The Contribution of Neuromarketing to the Study of Consumer Behavior. Brazilian Business Review, 11(3), 123-143.

[11] Sebastian, V. (2014). Neuromarketing and Evaluation of Cognitive and Emotional Responses of Consumers to Marketing Stimuli. Procedia Social and Behavioral Sciences, 127, 753-757.

[12] Solnais, C., Andreu-Perez, J., Sánchez-Fernández, J., \& Andréu-Abela, J. (2013). The contribution of neuroscience to consumer research: A conceptual framework and empirical review. Journal of Economic Psychology, 36, 68-81.

[13] Perrachione, T. K., \& Perrachione, J. R. (2008). Brains and brands: Developing mutually informative research in neuroscience and marketing. Journal of Consumer Behaviour, 7(4-5), 303 - 318. 
[14] Ahmad, Z. A. (2010). Brain in Business: The Economics of Neuroscience. Malaysian Journal of Medical Sciences, 17(2), 1-3.

[15] Abd Hamid, A. I., Abdullah, J. M., \& Fauzan, N. (2018). The Future of Cognitive Neuroscience. International Journal of Engineering \& Technology, 7(3.22), 1-4.

[16] Esmailpour, H., \& Zakipour, M. (2016). The Sensory Stimuli Model; Engage with the Consumer Senses for Brand Distinguishes. Journal of Management Sciences, 2(4), 212-218.

[17] Colombo, S., Gorno, R., \& Bergamaschi, S. (2013). Enhancing Product Sensory Experience: Cultural Tools for Design Education. International Conference on Engineering and Product Design Education (pp. 698703). Dublin, Ireland: Dublin Institute of Technology.
[18] White, K., Habib, R., \& Hardisty, D.J. (2019). How to SHIFT Consumer Behaviors to be More Sustainable: A Literature Review and Guiding Framework. Journal of Marketing, 83(3), 22-49.

[19] Young, C. (2002). Brain Waves, Picture Sorts®, and Branding Moments. Journal of Advertising Research, 42(4), 42-53.

[20] Wang, L. (2019). Test and Evaluation of Advertising Effect Based on EEG And Eye Tracker. Translational Neuroscience, 10, 14-18.

[21] Wang, R. W. Y., Chang, Y., Chuang, S. (2016). EEG Spectral Dynamics of Video Commercials: Impact of the Narrative on the Branding Product Preference. Scientific Reports, 6, 36487. 